Paweł Scheffler, Implementing Bilingual Pattern Practice, RELC Journal Volume 47, 2016 - Issue 2, pp. 253-261. Copyright (C) The Author 2015. Reprinted by permission of SAGE Publications. http://journals.sagepub.com/doi/full/10.1177/0033688215612001

\title{
Implementing bilingual pattern practice
}

\begin{abstract}
This article describes how semi-communicative bilingual drills were implemented in a four-month course in pedagogical English grammar. In the course, a group of ten Polish adult learners participated. When the course was over, the learners were asked to evaluate the procedure by filling in a questionnaire. In the questionnaire, they expressed overwhelming approval for bilingual drills in terms of their usefulness. Some of the students indicated that the drills prepared them for communication in English.
\end{abstract}

\section{Keywords}

Pattern practice, bilingual drills, mother tongue, grammar instruction

\section{The teaching context}

The author of this report is a university lecturer and researcher in Poland. Apart from courses in linguistics, he teaches English as a foreign language, including courses in pedagogical English grammar. It was in one of the grammar courses that the author experimented with bilingual pattern practice as proposed by Butzkamm and Caldwell (2009).

The course taught by the author was a four-month course in pedagogical English grammar. During that period the class received 30 hours of instruction. The aim of the 
course was to review and expand the students' knowledge of selected English verbal and nominal categories (i.e. tenses, voice, nouns and articles). The students attended other English classes at the same time (e.g. speaking classes), which were not, however, aligned with the grammar course in any way. The students were ten adult learners from a mixedability (mostly intermediate) EFL pedagogical grammar class taught by the author in a higher school of professional education in Poland. There were ten students in the group, aged 20-21, seven of whom were female, and three of whom were male.

\section{Reason for the innovation}

In the author's teaching context pedagogical English grammar courses are a regular feature on the curriculum. These courses largely focus on rules and explanations, and typically, the only practice that learners are engaged in is controlled written practice. That seemed highly inadequate to the author: in the light of research findings like those of Spada and Tomita (2010), for explicit grammar instruction to work best it should include plenty of opportunities for proceduralizing declarative knowledge, leading ultimately to automaticity. This means communicative speaking activities, i.e. activities that resemble real-life language use which at the same time provide 'massive repetition experiences' (Segalowitz 2003: 402). The question, then, was how to reconcile the requirement for 'massive repetition' with communicative language use.

\section{The innovation}

The author thus started to investigate possible options for combining communication with repetition in his grammar courses. Massive repetition was, of course a distinctive feature of the Audiolingual method in the 1960s, and this was the first avenue the author explored. 
The Audiolingual method appealed to structuralist linguistic theory for its description of language and to behaviourism for its learning theory. This resulted in grammatical structures being first introduced to learners in dialogues and then practised orally through drills which required, for example, repetition or replacement. The drills were, however, frequently mechanical, that is, they could be performed without paying any attention to meaning. That was probably one of the reasons why many learners could not transfer classroom language skills to real life contexts, which ultimately led to the demise of Audiolingualism (Richards and Rodgers, 2001:65).

Pattern practice, however, need not be mechanical. In addition to mechanical drills, one can distinguish meaningful and communicative ones. In both of them, grammatical structures are manipulated in oral exercises. However, the former 'require the student to process meaning', the latter 'require conveying actual content unknown to the hearer' (DeKeyser, 1998: 50). An interesting combination of meaningful and communicative drills was proposed by Butzkamm and Caldwell (2009). They (2009: 124-130) developed a seven-step procedure which they refer to as semi-communicative bilingual drills. The steps in the procedure are as follows:

Step 1: presentation and clarification of a model sentence. The sentence may come from a dialogue or text that has already been covered by the class. It contains an exemplar of a selected construction whose structure and communicative function is clear to the learners.

Step 2: easy substitutions: meaningful substitution drills based on stimulus sentences in the mother tongue provided by the teacher. For example:

Teacher (Polish):

Co mam z tym zrobić?
Learner:

What shall I do with it? 
Step 3: pair work: students perform substitution drills in pairs with bilingual lists of sentences

Step 4: 'loaded' sentences and contextual diversity: substitution drills with more contentful sentences provided by the teacher. For example:

Teacher (Polish)

Co mam zrobić ze swoją żoną?

Co mam zrobić ze swoim życiem?
Learner:

What shall I do with my wife?

What shall I do with my life?

Step 5: 'Over to you': students invent their own examples

Step 6: Pupil presentation and communicative interludes: students present their sentences; the teacher's task is to stimulate communicative exchanges on the basis of the sentences produced by the students

Step 7: Creative writing: students compose short texts which include an example of the structure just practised

In steps 2-4, the procedure involves meaningful bilingual drills (which require learners to process meaning), and in step 7, controlled monolingual communicative practice (which requires learners to convey new information). The procedure is probably the most comprehensive recent attempt at implementing pattern practice in L2 instruction. Its central feature is the use of L1 stimulus sentences, which, as Butzkamm and Caldwell (2009: 124) say, are supposed to make learners focus on expressing ideas instead of merely practising syntactic patterns with gaps to be filled by vocabulary items, as was the case in the Audiolingual method. The teacher, then, provides learners with ideas in the mother tongue 
and the learners express them in the target language. In stages 6 and 7 learners are free to express their own ideas using the relevant constructions.

Communicative drills can be seen as a means of enabling learners to move from declarative knowledge of rules to procedural knowledge and fluent performance. Such an account appeals to conscious learning and general skill-acquisition theory. However, pattern practice can also be related to modern theories of language acquisition, one example being Hoey's (2005) lexical priming.

According to Hoey (2005: 13), language acquisition is driven by lexical priming, that is, a process in which learners subconsciously develop various associations between words in a language. These associations may be of lexical, grammatical, semantic and pragmatic nature, and they are formed 'as a result of the cumulative effects of an individual's encounters with the word'. As for grammar, it is in Hoey's (2005: 159) account "the accumulation and interweaving of the primings of the most common sounds, syllables and words of the language", that is, items like "is, was, the, $a$ and of, syllables like ing," etc.

In the case of L1 acquisition, learners' primings come from a huge variety of sources. By contrast, the sources of primings in L2 contexts are 'radically impoverished' (Hoey 2005: 185). Because of this discrepancy Hoey (2005: 186) says that L2 learners can be provided by language teaching materials and by teachers with 'essential shortcuts to primings' in the form of ' $[\mathrm{u}]$ sage notes, drilling exercises, texts or tapes with repeated instances of a word sequence' etc. Further, Hoey (2005: 187) suggests that producing output may reinforce or contribute to creating new primings. He concludes that if this is indeed the case, then 'the learner needs to speak or write as often as possible'.

The above has interesting implications for L2 teaching and for pattern practice in particular. During drilling exercises learners are exposed to repeated instances of selected sequences of words. If the drills are meaningful or communicative, then by listening to their classmates speak, learners receive large amounts of linguistically focused meaningful 
input, and by speaking themselves they produce large amounts of linguistically focused meaningful input. If Hoey (2005) is right, then such activities can lead to establishing new primings in the target language.

\section{Its effects}

Before the course, the author prepared sets of sentences in Polish for bilingual pattern practice dealing with the English verbal system. This area had been selected because the English tense system is a source of considerable difficulty for Polish learners of English, which probably results (at least to some extent) from the differences between English and Polish grammar. So, for example, during the course the students practised the English simple present, present continuous and passive voice in this way. The practice involved the production of affirmative, interrogative and negative sentences.

During the course, the author spent the first three months dealing with verbal structures and then one month discussing nominal categories. Bilingual pattern practice as described above was used regularly during the first three months. After completing the course and receiving the final grades, the students were administered an anonymous questionnaire in Polish, in which they were asked to evaluate the entire sequence of steps. The students received detailed written instructions in Polish on how to fill in the questionnaire. In the questionnaire, semantic differential scales were used in relation to three categories, based on Gardner (1985): general evaluation, utility and interest. There were five pairs of adjectives in each category and the questionnaire was a slightly modified version of one used by the author in another study (Scheffler, 2012). Table 1 presents the English translation of the Polish adjectives. 
Table 1: English translations of Polish adjectives

\begin{tabular}{lll}
\hline \multicolumn{1}{c}{ general evaluation } & \multicolumn{1}{c}{ utility } & \multicolumn{1}{c}{ interest } \\
\hline good - bad & useful - useless & interesting - uninteresting \\
agreeable - disagreeable & educational - uneducational & absorbing - monotonous \\
pleasant - unpleasant & needed - unneeded & exciting - boring \\
enjoyable - unenjoyable & necessary - unnecessary & varied - monotonous \\
nice - awful & effective - ineffective & inviting - off-putting \\
\hline
\end{tabular}

The students' answers were converted into numerical values on a one-to-seven scale, which was also used by Gardner (1985). In the process of conversion, seven points were awarded for extremely positive assessment (a check-mark right next to the adjective 'pleasant", for instance), and one point for extremely negative assessment (a check-mark right to the adjective 'unpleasant'). Neutral assessment, i.e. selecting the middle category, was worth four points. The conversion into numerical values made it possible to sum up individual item scores and produce total scores for each category. The minimum possible score for each category was five points, neutral assessment meant 20 points, and the maximum was 35 .

\section{Learners' evaluation}

The box-and-whisker plots in Figure 1 show the distribution of all the students' scores for the three categories. The box plots clearly demonstrate overwhelming approval for the procedure: there are no scores below the 20-point neutral assessment level in any of the three categories. 

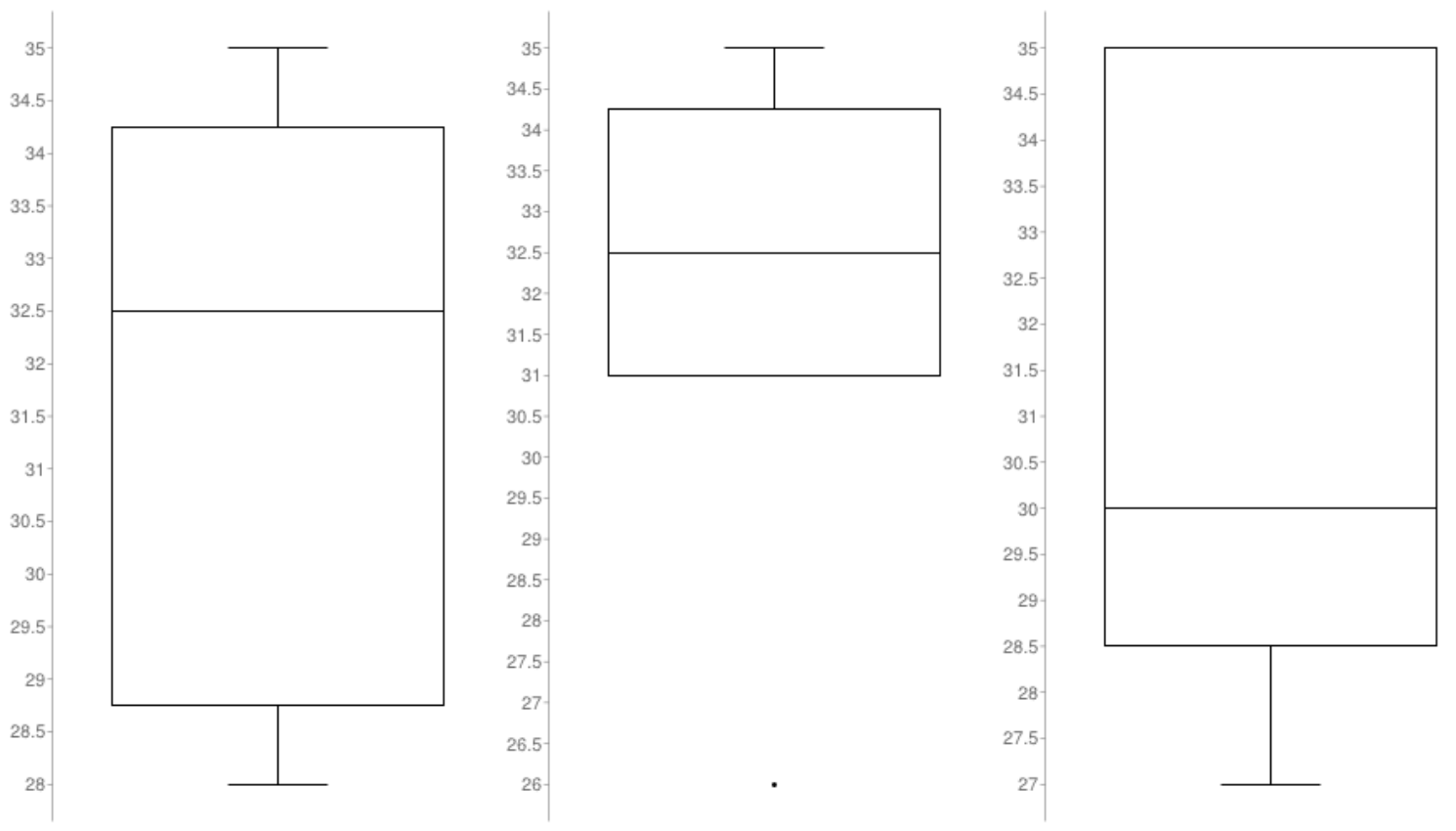

Figure 1: Students' assessment of bilingual pattern practice

In addition to the closed-ended items summarised above, the questionnaire also contained two Polish sentences for completion in which the students were asked to say what they liked and disliked the most about the procedure. All the students commented on the aspects of the procedure that they liked (translation mine):

What I liked best about the exercise was that

S1: it encouraged me to work

S2: it was interesting, it helped me concentrate 
S3: each student was able to practise, to review things, to learn things that were new or unclear

S4: thanks to this exercise one was able to commit grammatical structures to memory, which helps in speaking

S5: it helped me to learn grammar and I made progress

S6: there were a lot of different examples

S7: we were able to practise grammar orally, which helps to communicate better

S8: we had an opportunity to speak right after being asked to do so and that each of us participated

S9: there was interaction between us

S10: the teacher encouraged creativity

There were only three comments on the negative aspects, with one of them (S5) actually having a positive ring to it:

What I disliked the most about this exercise was that

S5: it was too short

S8: parts of it lasted too long

S9: pair work was not monitored closely enough by the teacher

The positive comments made by the students included two very interesting points. First, two students remarked that practising grammatical structures through oral drills helped them to prepare for speaking or communication in English. Second, another two students stressed interaction and creativity. That was a very welcome comment, as bilingual pattern practice should, according to Butzkamm and Caldwell (2009), lead to communicative exchanges in Step 6 of the procedure. At this stage, students prepare their own examples of 
the relevant structures and present them to the class. It is the teacher's responsibility to use these examples as starting points for communicative exchanges.

\section{Drills and communication}

During Step 6 of the procedure, the teacher created opportunities for communication and interaction between students in a number of different ways. One of them was by asking the students to write sentences about themselves which were either true or false. The task for the other learners was then to decide whether a given sentence was indeed true or false.

In order to monitor how the interaction proceeded, on two different occasions the communicative exchanges in Step 6 were audio-recorded and transcribed into standard English orthography by the author. The learners' consent had been obtained prior to the recordings. The had been informed that the recordings were needed to examine how they communicated during the class.

In the samples below, individual students were asked to present their sentences and the others were to determine whether they were true or false. The structure in focus was the present perfect. The students in the exchanges are referred to by their initials. $T$ stands for the teacher.

\section{Sample 1}

T: What is your sentence? (addressing a student)

S1: I have never seen an elephant.

T: An interesting example. What do you think?

S2: In my opinion, this .... this may be false because .... M .... isn't poor person.

T: And she keeps an elephant at home?

S2: No .... no, no, elephants in home [laughter] ... this is ... 
T: As a pet.

S2: No, [laughter] outside.

T: Outside, in the garden, you mean.

S2: Possibly.

T: OK. M, so do you keep an elephant in the garden?

S1: No, I don't. But I've seen a few in my life.

T: You have seen a few elephants in your life.

S1: In zoo.

T: In a zoo. Aha, so the sentence is false. How many elephants have you seen in your life?

S1: I think I could have seen about ten elephants in my life.

T: So quite a few elephants.

S1: But I'm older than the rest of our group, so I am more experienced.

$\mathrm{T}$ : Very, very interesting.

Sample 2

$\mathrm{T}: \mathrm{A}$, what is your sentence?

S1: I have had my driving licence for five years.

T: What do you think, is it true? (addressing the class)

S2: No, it is false.

T: Why do you think it's false?

S2: Five years ago A has ... A was 16.

T: OK, so five years ago A was 16 , right, and why is that a problem?

S2: Driving licence can passed after 18.

T: So you need to be 18 to take a driving test.

S2: Yes, obviously. 
As can be seen, the students and the teacher were involved in genuine exchanges of new information. At the same time, they were exposed to several instances of the target structures. The exchanges resemble DeKeyser's (1998: 52) monolingual communicative drills which 'require the student to use the language to convey real meaning, while some recently taught rules, the focus of the drill, can be kept in mind'.

The exercise also afforded the learners the opportunity to practise communicatively other structures which were not the target of instruction. On a number of occasions, this resulted in opportunities for noticing linguistic features. In sample two, S2 struggled to express the idea of taking a driving test. The teacher provided the relevant expression, which may have resulted in the student noticing it. Finally, the students themselves noticed accuracy problems with their output, which resulted in self-corrections (S2 in sample 2: 'Five years ago A has .... A was 16').

\section{Reflection}

The number of students participating in the course and filling in the questionnaire was, of course, very small, which is an obvious limitation of this report. However, the students were exposed to the procedure on a regular basis for three months in relation to a number of different grammatical structures and thus they can be expected to have made considered judgements.

Submitting new or little known teaching procedures to long-term classroom trials is certainly in line with Larsen-Freeman's (2015: 274) call for classroom research. Such research may not always have the rigour of true experimental studies, but it enables us to see how things work in 'the complex reality of the classroom'.

The fact that the students expressed support for the procedure means that its effectiveness should be investigated further in experimental studies. If pattern practice does help learners to produce language and to communicate, then it would also be interesting to 
examine whether, as predicted by Hoey's (2005) lexical priming theory, this is due to links being formed between the components of, for example, the present perfect or the passive construction.

For the author as a practitioner, the experience confirmed the claims of those who see a constructive role for the mother tongue in the foreign language classroom (e.g. Butzkamm and Caldwell, 2009; Butzkamm, 2011; Hall and Cook, 2012). It also made clear the need for a closer cooperation between the teachers in the school where the course was taught: had the grammar syllabus been aligned with the speaking class syllabus, then the learners could have been given more opportunities for communicative practice of selected grammatical categories.

\section{References}

Butzkamm W (2011) Why make them crawl if they can walk? Teaching with mother tongue support. RELC Journal 42(3): 379-391.

Butzkamm W, Caldwell JAW (2009) The Bilingual Reform: A Paradigm Shift in Foreign Language Teaching. Tübingen: Gunter Narr Verlag.

DeKeyser RM (1998) Beyond focus on form: Cognitive perspectives on learning and practising second language grammar. In Doughty CJ, Williams J (eds) Focus on form in classroom second language acquisition. Cambridge: Cambridge University Press, $42-63$.

Gardner RC (1985) The Attitude/Motivation Test Battery: Technical Report. Available at: http://publish.uwo.ca/ gardner/docs/AMTBmanual.pdf (accessed 19 January 2011).

Hall G, Cook G (2012) Own-language use in language teaching and learning. Language Teaching 45(3): 271-308.

Hoey M (2005) Lexical priming: a new theory of words and language. London: Routledge. 
Larsen-Freeman D (2015) Research into practice: Grammar learning and teaching. Language Teaching 48(2): 263-280.

Richards JC, Rodgers TS (2001) Approaches and methods in language teaching. Cambridge: Cambridge University Press.

Scheffler, P (2013) Learners' perceptions of grammar-translation as conscious raising. Language Awareness 22(3): 255-269.

Segalowitz N (2003) Automaticity and second languages. In: Doughty CJ, Long MH (eds) The Handbook of Second Language Acquisition. Malden, MA and Oxford, UK: Blackwell, 382-408.

Spada N, Tomita Y (2010) Interactions between the type of instruction and type of language feature: A meta-analysis. Language Learning 60(2): 263-308. 